\title{
MAPEAMENTO DAS PRODUÇÕES ACADÊMICAS SOBRE CONDIÇÕES DE TRABALHO DO COORDENADOR PEDAGÓGICO (2012 A 2016)
}

\author{
Eliane Guimarães de Oliveira? \\ Claudio Pinto Nunes²
}

\section{RESUMO}

Este estudo faz parte da pesquisa em construção sobre as condições de trabalho do coordenador pedagógico e tem por objetivo apresentar um mapeamento das produções acadêmicas referentes a temática no recorte temporal de 2012 a 2016. Para realização do trabalho foi feita pesquisa no banco de teses e dissertações da Capes com o descritor: condições de trabalho do coordenador pedagógico, sendo localizado um total de 56 trabalhos, sendo 45 dissertações e 11 teses, estando o número maior de produções na região Sudeste. Na leitura dos títulos, resumos e palavras-chave, identificamos diversas nomenclaturas para o coordenador pedagógico e o principal conteúdo abordado nos trabalhos é a formação continuada. Somente uma dissertação trata de forma específica sobre as condições de trabalho do supervisor escolar, discutindo componentes como: forma de ingresso, jornada de trabalho, carreira e remuneração. Diante do mapeamento realizado, fica evidenciado a lacuna desse debate no campo de pesquisa e a necessidade de novos estudos.

Palavras-chave: Condições de Trabalho. Coordenador Pedagógico. Produções Acadêmicas.

\section{MAPPING OF ACADEMIC PRODUCTIONS ON WORKING CONDITIONS OF THE}

\section{PEDAGOGICAL COORDINATOR (2012 TO 2016)}

\begin{abstract}
This study is part of the ongoing research about the working conditions of the pedagogical coordinator and it aims to present a mapping of the academic productions concerning the theme in the temporal cut from 2012 to 2016. In order to perform the work one did research in CAPES bank of theses and dissertations with the descriptor: working conditions of the pedagogical coordinator, locating a total of 56

\footnotetext{
1 Mestranda em Educação na Universidade Estadual do Sudoeste da Bahia (UESB); pedagoga da Universidade do Estado da Bahia (UNEB); coordenadora pedagógica da Rede Pública Municipal de Ensino de Guanambi - Bahia; membro do Grupo de Estudos sobre Didática, Formação e Trabalho Docente (Difort). E-mail: elianegbi@yahoo.com.br

2 Doutor em Educação; Professor Titular da Universidade Estadual do Sudoeste da Bahia (UESB); docente do Programa de Pós-Graduação em Educação da UESB; líder do Grupo de Estudos sobre Didática, Formação e Trabalho Docente (Difort). E-mail: claudionunesba@hotmail.com
} 
works, 45 dissertations and 11 theses, the greatest number being productions from the Southeast region. Upon reading the titles, abstracts and keywords we identified several nomenclatures for the pedagogical coordinator and the main content approached in the works is continued training. Only one dissertation deals specifically with the working conditions of the school supervisor, discussing components such as: admission process, working hours, carrier and remuneration. In front of the mapping done, one evidenced the lack of this debate in the research field and the need of new studies.

Keywords: Working Conditions. Pedagogical Coordinator. Academic Productions.

\section{MAPEO DE LAS PRODUCCIONES ACADÉMICAS ACERCA DE LAS CONDICIONES DE TRABAJO DEL COORDINADOR PEDAGÓGICO (2012 A 2016)}

\section{RESUMEN}

Este estudio forma parte de una investigación en curso acerca de las condiciones de trabajo del coordinador pedagógico y tiene como objeto presentar un mapeo de las producciones referentes al tema en el recorte temporal de 2012 a 2016 . Para la realización del trabajo se hizo una investigación en el banco de datos de tesis y disertaciones de CAPES con el descriptor: condiciones de trabajo del coordinador pedagógico, siendo halladas un total de 56 trabajos, siendo 45 disertaciones y 11 tesis, siendo el número más grande de producciones en la región Sudeste. En la lectura de los títulos, resúmenes y palabras-clave identificamos diversas nomenclaturas para el coordinador pedagógico y el principal contenido abordado en los trabajos es la formación continua Solamente una disertación trata específicamente acerca de las condiciones de trabajo del supervisor escolar, discutiendo componentes como: forma de ingreso, jornada de trabajo, carrera y remuneración. Mediante el mapeo realizado, se evidencia un vacío en el campo de investigación y la necesidad de nuevos estudios.

Palabras clave: Condiciones de Trabajo. Coordinador Pedagógico. Producciones Académicas.

\section{INTRODUÇÃO}

A discussão sobre as condições de trabalho docente faz parte do debate sobre valorização do Magistério. Leheh (2010) considera que a expressão valorização do Magistério é muito usada nos discursos de escolas, sindicatos, governos, imprensa e abrange condições objetivas e subjetivas de trabalho. Entre as condições objetivas o autor cita as condições de trabalho, sendo esta um direito dos profissionais do Magistério público brasileiro, conforme preconiza a Lei n9.394/1996 (BRASIL, 1996). 
Segundo Oliveira e Assunção (2010), as condições de trabalho dizem respeito não apenas a estrutura física, materiais e equipamentos e outros tipos de apoio necessário à produção, mas também as relações de emprego, incluindo formas de contratação, remuneração, carreira e estabilidade. As autoras consideram que a análise sobre as condições de trabalho devem se situar no tempo e no espaço, levando em conta o contexto histórico-social e econômico que as engendram.

Desse modo, o estudo sobre as condições de trabalho do coordenador pedagógico requer mais do que pensar sobre a estrutura do lócus de atuação desses docentes e suas relações contratuais. Uma pesquisa nessa direção requer ainda uma análise da conjuntura históricosocial e econômica do contexto onde se insere o trabalho desse profissional.

Nesse sentido, consideramos pertinentes as contribuições de Oliveira e Assunção (2010) quando estas autoras chamam atenção para o fato de que discutir condições de trabalho de modo geral e de modo específico as condições de trabalho docente no contexto atual implica em considerar que tais condições resultam da organização social, sendo a mesma definida em suas bases econômicas pelo modo de produção capitalista.

Na visão de David Harvey (1992) o capitalismo sofreu mudanças no final do século XX em função do colapso do sistema fordista-Keynesiano e entre o período de 1965 e 1973 fica evidente a dificuldade desse sistema em conter as contradições do capitalismo e o problema apontado é a rigidez das relações do trabalho, capital e governo. Nesse cenário de crise houve reestruturação econômica e reajustamento social e político com surgimento de um regime de "acumulação flexível", que se apoia na flexibilidade dos processos de trabalho, dos mercados, dos produtos e padrões de consumo. Caracteriza-se pelo surgimento de setores de produção novos, novas maneiras de fornecimento de serviços financeiros, novos mercados e taxas de inovação comercial, tecnológica e organizacional. O autor destaca as consequências do novo regime para os trabalhadores, com aumento do desemprego, subcontratação e enfraquecimento dos sindicatos, advindos 
de deslocamento geográfico dos centros industriais e retorno a antigas formas de trabalho, como o familiar e doméstico.

A acumulação flexível apresentada por Harvey (1992) é tratada por Anderson (1995) como neoliberalismo, sendo este um sistema que coloca a necessidade de disciplina orçamentária, contenção de gastos com bemestar, restauração de taxa de desemprego e reformas fiscais que resultem em crescimento das taxas dos países. Tratando sobre o neoliberalismo, Anderson (1995) explicita a sua hegemonia em todo o mundo, sendo adotado inicialmente apenas por governos de direita da Europa, mas posteriormente vai ocupando cada vez mais espaços, sendo adotado também por governos social-democratas.

A partir das influências neoliberais, a educação sofre reformas estruturais, de modo que as políticas de educação assumem uma posição de subordinação à lógica econômica, sendo esta uma das marcas do neoliberalismo que se instaurava na gestão pública dos anos 1990. Nesta perspectiva, o contexto neoliberal provocou reformas do Estado, com mudança em seu papel, que assume a natureza de Estado Mínimo e passa da função de regulamentador a de regulador.

O Estado regulamentador se preocupa mais com controle dos processos e menos com resultados, sendo o regulador o inverso. A partir de pesquisas, Barroso (2005) demonstra que os modos de regulação das políticas educativas em um contexto político neoliberal adotado é o pósburocrático, tendo este dois referenciais principais: o Estado avaliador e $\circ$ quase-mercado. No Estado avaliador a regulação passa a centrar menos no controle e mais nos resultados, no quase-mercado há a substituição da regulação estatal pela de iniciativa privada.

No Brasil as políticas neoliberais são adotadas através de reformas do Estado na década de 1990, principalmente a partir do Governo Fernando Henrique Cardoso. Segundo Peroni (1993), as políticas adotadas pelo governo nessa década beneficiam as elites e o Estado é mínimo apenas para as políticas sociais. Assim, o Governo FHC apresenta a reforma do Estado, propondo a substituição da administração pública burocrática pela 
gerencial, que utiliza a lógica do mercado, sendo os serviços sociais como educação descentralizados na lógica do neoliberalismo. Nesse modelo de educação mercantilista e pós-burocrático, os profissionais da educação são cada vez mais responsabilizados pelos resultados do processo educacional, gerando situações de acúmulo de atividades e sobrecarga de trabalho.

Dublante e Sousa (2017) chamam a atenção para a necessidade de se refletir no campo educacional sobre as alterações nas políticas educacionais que são fruto dessas tendências e cita como exemplo políticas de formação docente que vem tomando o mercado como modelo, além de estratégias como descentralização, inovações na gestão, na coordenação pedagógica e na docência e novas responsabilidades aos profissionais da educação básica.

Essas novas responsabilidades advindas das políticas educacionais têm transformado o trabalho docente, trazendo uma complexidade muito maior. Pini e Melo (2011) consideram que as transformações implicam mudanças na organização e no trabalho escolar. Segundo as autoras,

\begin{abstract}
Através de numerosas normas, as novas políticas educacionais - com frequência de caráter impositivo - estão colocando os docentes diante de novas situações no trabalho que refletem novas demandas e necessidades e acarretam a ampliação do trabalho para além da condução das aulas e atividades relacionadas, sem que sejam oferecidas as condições de trabalho adequadas para tal (PINI; MELO, 2011, p. 56).
\end{abstract}

Uma análise do texto da Lei de Diretrizes e Bases da Educação Nacional (LDBEN), Lei $n^{\circ}$ 9.394/1996, mostra que ao Magistério cabe o exercício das funções de docente, direção de unidade escolar e coordenação e assessoramento pedagógico, sendo os diretores e coordenadores pedagógicos considerados especialistas que necessitam de experiência de regência de classe (BRASIL, 1996).

Notamos que a partir dessas políticas ao professor não cabe apenas o ato de ensinar, mas exercer outros papeis como gestor escolar e coordenador pedagógico, e para tanto necessita de compreensão dessas funções. Na visão de Dias e Rocha (2017) trata-se de uma situação de 
exploração do trabalho docente num contexto capitalista, pois o aumento do trabalho não é acompanhado de melhorias salariais e valorização.

Essas demandas aparecem no contexto escolar permeadas pelo discurso da democratização e da descentralização e acompanhadas de um processo de responsabilização que delega às escolas e docentes a responsabilidade por resultados, num contexto em que o Estado é cada vez menor no financiamento de políticas educacionais, gerando aos profissionais do Magistério intensificação e condições de trabalho cada vez mais precárias. A responsabilização dos professores pelos sucesso/fracasso do processo escolar reverbera no aumento do volume de trabalho e sua precarização.

A partir dessas abordagens, discutimos neste estudo a condição de trabalho do coordenador pedagógico na mesma linha da discussão sobre trabalho docente, pois este é, do ponto de vista da legislação (BRASIL, 1996) um professor, tanto em termos de formação como de experiência. Como abordam Oliveira e Vieira (2012), o trabalho docente não se restringe mais à atividade de ensino de uma disciplina em uma sala de aula, pois as escolas estão cada vez mais complexas e exige dos docentes outras funções e competências. Essas autoras definem condição de trabalho docente como

[...] a forma como está organizado o processo de trabalho nas unidades educacionais, compreendendo escolas, pré-escolas, creches e outros espaços em que se desenvolve o trabalho educativo. Tais condições compreendem aspectos relativos à forma como o trabalho está organizado, ou seja, a divisão das tarefas e responsabilidades, a jornada de trabalho, os recursos materiais disponíveis para o desempenho das atividades, os tempos e espaços para a realização do trabalho, até as formas de avaliação de desempenho, horários de trabalho, procedimentos didáticopedagógicos, admissão e administração das carreiras docentes, condições de remuneração, entre outras. A divisão social do trabalho, as formas de regulação, controle e autonomia no trabalho, estruturação das atividades escolares, a relação número de alunos por professor, também podem ser compreendidas como componentes das condições de trabalho docente (OLIVEIRA; VIEIRA, 2012, p. 157).

Considerando que o coordenador pedagógico é um docente por formação e até por experiência profissional, conforme explicita a legislação, 
podemos considerar semelhantes os componentes das condições de trabalho do professor e do coordenador pedagógico. Todavia, é preciso explicitar que o docente que atua na coordenação pedagógica tem atividades específicas que se diferencia do exercício da docência e, nesse sentido, é preciso refletir sobre essa atuação e as condições de trabalho desse profissional, incluindo nessa reflexão a análise da estrutura e os materiais utilizados pelo coordenador no exercício de seu trabalho, assim como as relações de emprego a que estão submetidos, dentro de um contexto de flexibilização nas relações de trabalho, as quais ameaçam direitos conquistados pelos trabalhadores ao longo de anos de lutas.

Analisando o papel do coordenador pedagógico no contexto escolar, assim como o percurso histórico desse profissional, notamos que até início da década de 1990 sua atuação era voltada a supervisão no sentido de fiscalização do trabalho dos professores (SAVIANI, 2000).

A partir da década de 1990, temos no Brasil a adoção pelo governo brasileiro do modelo gerencialista de administração, chegando o mesmo a educação e provocando a intensificação do trabalho docente, com novas atribuições, sem ampliação de remuneração tanto para aqueles que atuam na regência de classe como também na coordenação pedagógica.

Desse modo, a partir desse contexto, o coordenador pedagógico passa a ser responsabilizado por uma série de atividades, entre elas a articulação da relação entre a família e a escola, a liderança da equipe, o acompanhamento e assessoramento das atividades docentes, a construção do Projeto Político-Pedagógico e a formação continuada, sendo esta recomendada pelo Banco Mundial numa visão economicista que a vê como menor custo-benefício (CAMPOS, 2015).

Domingues (2014) considera que a coordenação pedagógica é relativamente conhecida, com consenso nas atribuições desse profissional, porém há dispersão nos estatutos, faltando unidade que sintetize os aspectos conceituais, estruturais e políticos da ação desse profissional. A autora considera que a coordenação tem uma serie de atividades normalmente descritas nos regimentos das escolas, destacando entre as mesmas, 
[...] responder pelas atividades pedagógicas da escola; acompanhar na sala de aula a atividade do professor; supervisionar a elaboração de projetos; discutir o projeto político-pedagógico; prestar assistência ao professor; coordenar reuniões pedagógicas; organizar as turmas de alunos e acompanhar os processos de avaliação; organizar a avaliação da escola; cuidar da avaliação do corpo docente e do plano pedagógico; atender a pais e alunos em suas dificuldades; e propor e coordenar ações de formação contínua do docente na escola, considerando a relação intrínseca entre o fazer pedagógico e a reflexão sobre a prática educativa (DOMINGUES, 2014, p. 15-16).

Nesse cenário, a partir de lutas e reivindicações em diferentes momentos por parte de movimentos do magistério público brasileiro, algumas legislações brasileiras vão garantir direitos à valorização, como o piso salarial profissional, ingresso na carreira por meio de concurso público, plano de carreira, formação e condições de trabalho adequadas aos profissionais do Magistério, sendo os mesmos definidos como

[...] aqueles que desempenham as atividades de docência ou as de suporte pedagógico à docência, isto é, direção ou administração, planejamento, inspeção, supervisão, orientação e coordenação educacionais, exercidas no âmbito das unidades escolares de educação básica, em suas diversas etapas e modalidades, com a formação mínima determinada pela legislação federal de diretrizes e bases da educação nacional (BRASIL, 2008).

Assim, do ponto de vista legal o docente que atua na coordenação pedagógica na educação básica tem os mesmos direitos à valorização que tem os docentes que atuam em sala de aula. Mas no contexto de atuação, como isso ocorre de fato? Essas legislações significam melhoria das condições de trabalho do coordenador pedagógico?

Ao analisarmos a pesquisa "Trabalho docente na Educação Básica no Brasil" realizada pelo Gestrado/UFMG, que entrevistou 8.795 sujeitos docentes em sete estados brasileiros, observamos como resultados que as condições de trabalho dos professores que atuam na educação básica são inadequadas, não há cumprimento da legislação no que se refere às relações de trabalho, remuneração, ingresso na carreira, jornada de trabalho e plano de carreira (OLIVEIRA; VIEIRA, 2012). 
Um aspecto que vale a pena destacar nessa importante pesquisa do Gestrado é o fato de que a mesma tem como foco a análise das condições de trabalho de professores, mas não há referência específica às condições de trabalho do coordenador pedagógico.

Diante disso e tendo em vista a construção de pesquisa sobre as condições de trabalho do coordenador pedagógico, consideramos como imprescindível conhecer e trazer para a cena o que tem sido produzido sobre o tema. Para tanto, recorremos à realização de uma pesquisa do tipo Estado da Arte sobre a temática, uma vez que esse tipo de estudo "tem por objetivo realizar levantamentos do que se conhece sobre um determinado assunto a partir das pesquisas realizadas em uma determinada área" (VOSGERAU; ROMANOWSKI, 2014, p. 171).

Considerando a importância desse tipo de estudo, esse artigo apresenta um mapeamento de teses e dissertações da Capes sobre as condições de trabalho do coordenador pedagógico, produzidas no período entre 2012 e 2016.

\section{Mapeamento das produções acadêmicas: o que revelam as Teses e dissertaçōes}

Para a realização do mapeamento das produções acadêmicas sobre as condições de trabalho do coordenador pedagógico foi feita uma pesquisa no Banco de teses e dissertações da CAPES, utilizando como recorte temporal os últimos cinco anos, ou seja, de 2012 a 2016 , considerando que nos últimos anos o estudo sobre condições de trabalho tem se intensificado mais.

Para a pesquisa, foi escolhido como descritor "Condições de trabalho do coordenador pedagógico", sendo encontrado um total de 987.170 produções. Observando que a grande maioria das produções não se aproximava do tema em foco, utilizamos como delimitadores os campos: Tipo: Mestrado (dissertação) e logo após Doutorado (tese), ano: 2012, 2013, 2014, 2015 e 2016, grande área de conhecimento: Ciências Humanas, área de conhecimento e concentração: Educação. 
Com a delimitação fizemos a busca por dissertações e em seguida por teses, sendo localizadas um total de 10.702 trabalhos, dos quais 7.524 eram dissertações de Mestrado e 3.178 teses de doutorado. Entre as dissertações identificamos 45 relacionadas com a temática e entre as mesmas apenas uma que trata especificamente do tema condições de trabalho do coordenador pedagógico. Entre as mais de 3000 teses encontramos 11 que dialogam com o tema da pesquisa por abordarem a atividade realizada pelo coordenador pedagógico e nenhuma específica tratando da temática.

Em nossa análise realizamos a leitura do resumo das 45 dissertações e 11 teses, totalizando 56 trabalhos. Na leitura dos resumos buscamos identificar, além do tema da pesquisa, os seus objetivos, metodologia, referencias teóricos e resultados apresentados. Os quadros abaixo demonstram os dados extraídos das produções.

Quadro 1: Teses

\begin{tabular}{|c|c|c|c|c|c|c|c|}
\hline \multicolumn{2}{|c|}{ Objetivo } & \multicolumn{2}{c|}{ Metodologia } & \multicolumn{2}{c|}{ Referencial teórico } & \multicolumn{2}{c|}{$\begin{array}{r}\text { Resultado } \\
\text { apresentado }\end{array}$} \\
\hline Presente & ausente & Presente & ausente & Presente & ausente & Presente & ausente \\
\hline 11 & - & 9 & 2 & 8 & 3 & 11 & - \\
\hline
\end{tabular}

Fonte: Elaborado pelos autores, 2017.

Conforme observamos no quadro, nos resumos das 11 teses analisadas constam objetivos e resultados da pesquisa. No que se refere à metodologia, 9 trabalhos apresentam e 2 não trazem o método. Na especificação metodológica são citados: 2 estudos de natureza qualitativa, 3 estudos de caso, 2 materialismo histórico-dialético, 1 estudo do tipo etnográfico e 1 abordagem (auto)biográfica. No referencial teórico destacamos os autores que aparecem em mais de uma tese, sendo os mesmos: Ball e Nóvoa.

Quadro 2: Dissertações

\begin{tabular}{|c|c|c|c|c|c|c|c|}
\hline \multicolumn{2}{|c|}{ Objetivo } & \multicolumn{2}{c|}{ Metodologia } & \multicolumn{2}{c|}{ Referencial teórico } & \multicolumn{2}{c|}{ Resultado apresentado } \\
\hline Presente & ausente & Presente & ausente & Presente & ausente & Presente & ausente \\
\hline 42 & 3 & 33 & 12 & 22 & 23 & 39 & 6 \\
\hline
\end{tabular}

Fonte: Elaborado pelos autores, 2017. 
Analisando os dados contidos nos resumos das dissertações observamos que um número expressivo entre os 45 trabalhos apresentam objetivo. O mesmo se dá em relação aos resultados.

A metodologia presente já não é tão expressiva, constando em 33 dos 45 resumos. Entre os 33 trabalhos temos 26 que são de natureza qualitativa, 1 se referenda na Epistemologia qualitativa de Gonzalez Rey, 1 em estudos Foucaltianos, 4 estudos de caso e 1 se intitula como quanti-qualitativo.

Em se tratando dos referenciais teóricos, a maior parte dos resumos não apresentam, sendo que apenas 22 contem esses referenciais, sendo os autores mais citados: Imbernón, Libâneo, Placco e Almeida, Saviani, Franco, Placco, Freire, Lima, Nóvoa, Gatti, Zeichner, Monteiro, Freire, Sacristán, Contreras, Pimenta, Tardif, Veiga.

No que se refere aos anos de produção das teses e dissertações, no período de 2012 a 2016 observamos os dados ilustrados no gráfico abaixo.

Gráfico 1: Teses e dissertações produzidas entre 2012 e 2016
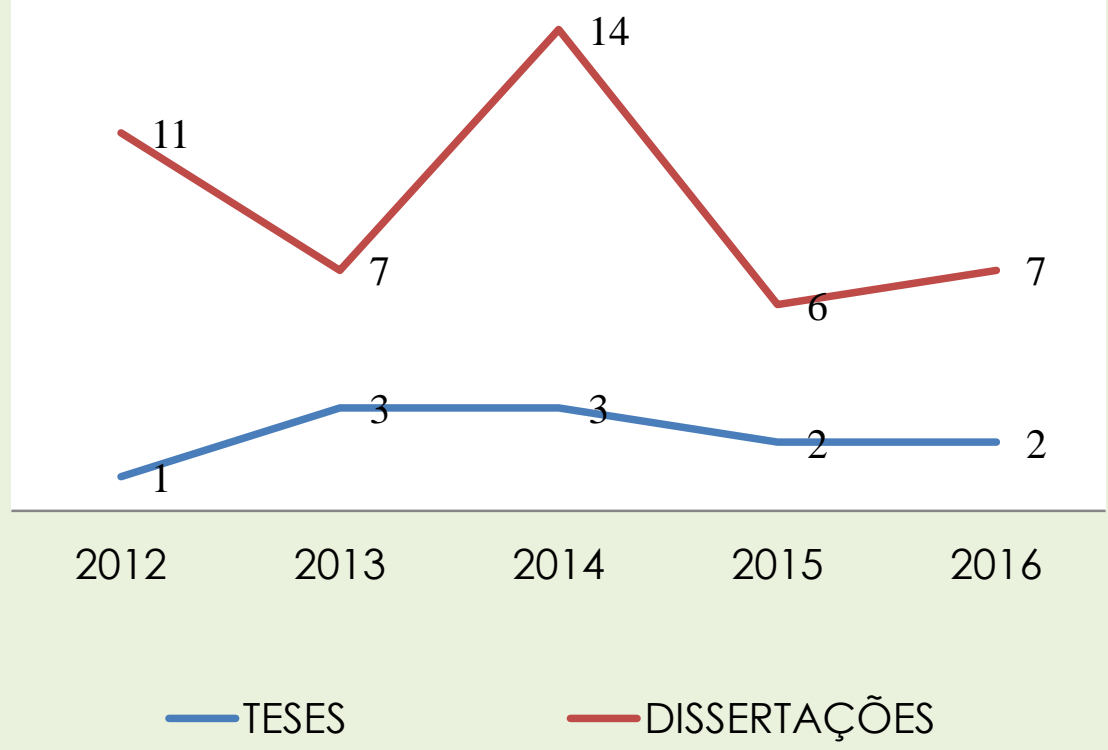

Fonte: Elaborado pelos autores, 2017.

Uma análise dos dados nos leva a perceber uma oscilação no número das produções acadêmicas entre os anos de 2012 e 2016 em temáticas relacionadas às condições de trabalho do coordenador pedagógico, uma 
vez que, entre as dissertações, temos um crescimento considerável de trabalhos no ano de 2014, atingindo um total de 14, o mesmo ocorrendo com as teses que cresce de 1 em 2012 para 3 em 2013 e 2014. Já em 2015 e 2016 há um declínio, em se tratando das dissertações passa a 6 em 2015 e 7 em 2016 e em relação as teses temos 2 em cada um desses anos.

Outro dado que consideramos importante demonstrar é em relação às regiões do Brasil onde foram produzidos esses trabalhos acadêmicos, conforme ilustra o gráfico abaixo.

Gráfico 2: Teses e dissertações produzidas por regiões do Brasil

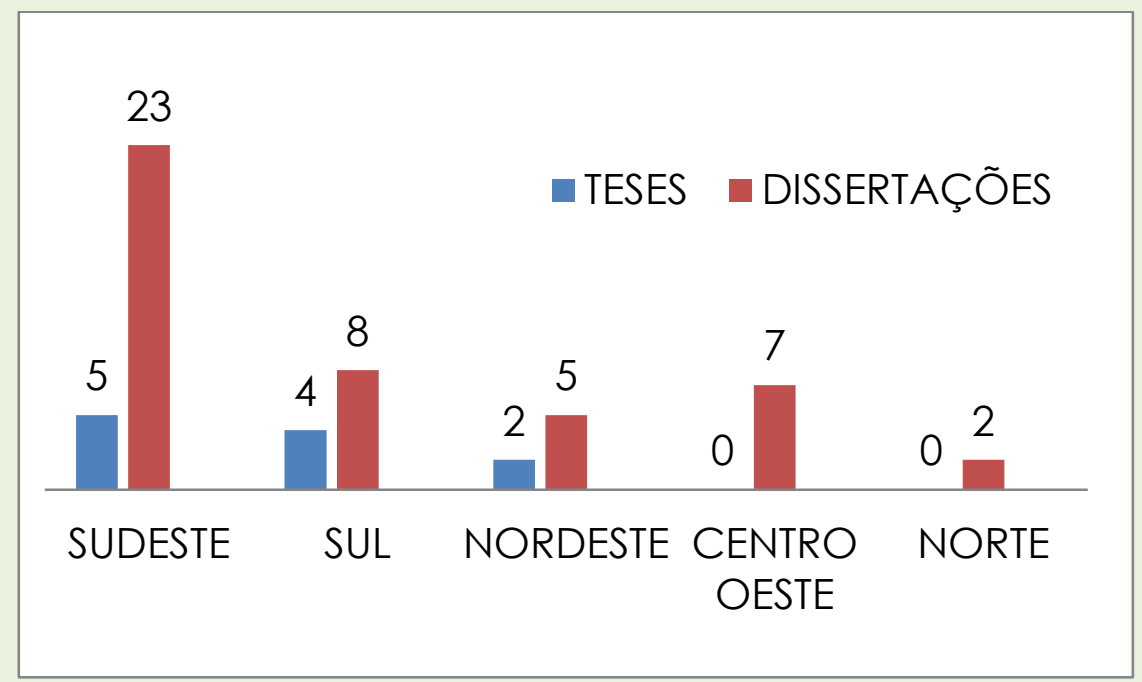

Fonte: Elaborado pelos autores, 2017.

Fica evidenciado no gráfico que a região com maior número de produções é a Sudeste, com $50 \%$ do total de trabalhos entre teses e dissertações produzidas entre 2012 e 2016. Em seguida temos a região Sul, com $21,4 \%$ dos trabalhos, Nordeste e Centro Oeste seguem com 12,5\% cada uma, sendo que não há nenhuma tese nessa última região. Por fim temos a região Norte com 3,6\% do total, sendo apenas 2 dissertações e nenhuma tese. Acreditamos ser o número de produções expressivo na região Sudeste em decorrência da maior quantidade de cursos de pós-graduação ofertados nessa região.

Além dos espaços onde foram produzidos os trabalhos, consideramos importante destacar que a leitura dos títulos, dos resumos e das palavras 
chaves nos levou a observar a existência de uma diversidade de denominações para o trabalho de coordenação pedagógica, conforme mostram os gráficos,

Gráfico 3: Denominações do trabalho de coordenador pedagógico nas teses

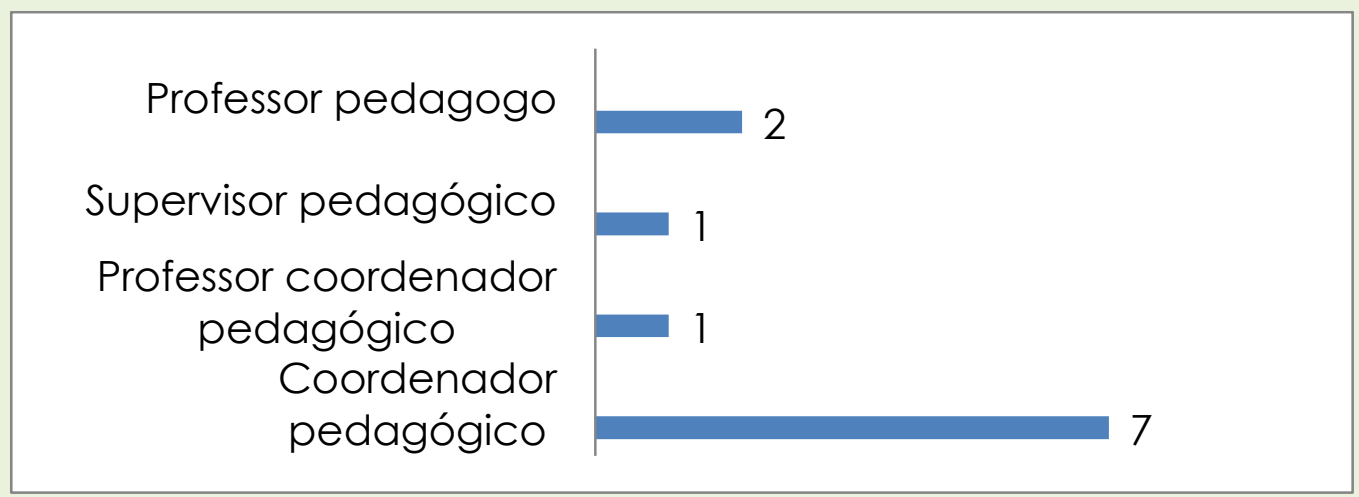

Fonte: Elaborado pelos autores, 2017.

Com relação às dissertações, temos os seguintes dados no que se refere às denominações do profissional que atua no assessoramento pedagógico.

Gráfico 4: Denominações do trabalho de coordenador pedagógico as dissertações

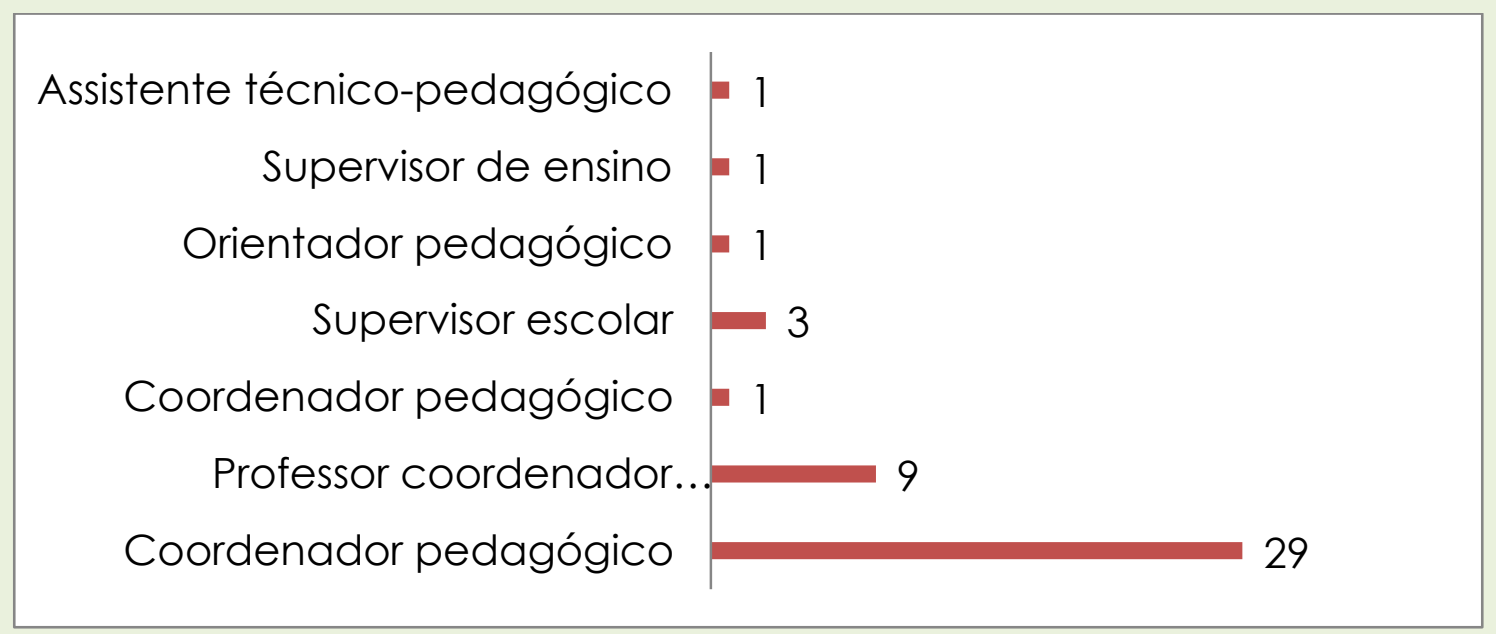

Fonte: Elaborado pelos autores, 2017. 
Observando os dados notamos que há oito nomenclaturas referentes ao trabalho da coordenação pedagógica, sendo as mesmas: coordenador pedagógico, professor coordenador pedagógico, supervisor pedagógico, professor pedagogo, supervisor escolar, orientador pedagógico, supervisor de ensino e assistente técnico-pedagógico.

Esses dados coadunam com as colocações de Domingues (2014) quando coloca que no contexto escolar há uma diversidade de designação dos profissionais que exercem a função de coordenar o trabalho pedagógico nas escolas, sendo comum no cenário acadêmico e político nacional a assunção por estes profissionais da atividade de formação continuada dos professores na escola. Em todos os trabalhos analisados há essa característica de trabalho com a formação docente.

Essa diversidade quanto à denominação aparece em legislações como a Lei de Diretrizes e Bases Lei $n^{\circ}$ 9.394/1996 que faz referência a atividades não apenas de coordenação, mas também inspeção, supervisão e orientação educacional.

Podemos considerar também a diversidade de nomenclaturas como resquício das políticas de formação do profissional para atuar no trabalho pedagógico da escola estipulada em 1968, através da Lei n 5.540, que mudou o currículo do curso de Pedagogia, o qual passou a oferecer habilitações técnicas para a formação de especialistas em orientação educacional, administração, supervisão e inspeção escolar, além da formação de professores para as escolas normais. Essas mudanças foram ratificadas pelo Parecer CFE n² 252/1969 e não estão mais em vigor, pois temos novas diretrizes curriculares do curso de Pedagogia (Resolução CNE/CP n 1/2006) que destina à formação do Pedagogo

[...] para exercer funções de magistério na Educação Infantil e nos anos iniciais do Ensino Fundamental, nos cursos de Ensino Médio, na modalidade Normal, de Educação Profissional na área de serviços e apoio escolar e em outras áreas nas quais sejam previstos conhecimentos pedagógicos (BRASIL, 2006). 
Além disso, a Resolução n 02/2015 que define as Diretrizes Curriculares Nacionais para a formação inicial em nível superior (cursos de licenciatura, cursos de formação pedagógica para graduados e cursos de segunda licenciatura) e para a formação continuada, no artigo $8^{\circ}$ estipula que o(a) egresso(a) dos cursos de formação inicial em nível superior deve estar a apto (a) a, entre outros aspectos,

\begin{abstract}
IX - atuar na gestão e organização das instituições de educação básica, planejando, executando, acompanhando e avaliando políticas, projetos e programas educacionais e X - participar da gestão das instituições de educação básica, contribuindo para a elaboração, implementação, coordenação, acompanhamento e avaliação do projeto pedagógico" (BRASIL, 2015).
\end{abstract}

Apesar de não estarem em vigor, as legislações da década de 1960 citadas anteriormente parecem estar ainda repercutindo na adoção de nomenclaturas dos profissionais que exercem o trabalho pedagógico. As teses e dissertações analisadas em diferentes redes de ensino localizadas em diversas regiões do país demonstram o uso de termos dessas legislações em diferentes redes de ensino por todo o Brasil. A LDB atual, promulgada em 1996, conforme expomos, ainda faz referência a diferentes nomenclaturas, apesar de haver uma certa predominância da expressão "coordenação pedagógica".

Mesmo sendo um número considerável de nomenclaturas para denominar aqueles que realizam o trabalho pedagógico nas escolas, nas teses e dissertações podemos identificar um número significativo de trabalhos que se referem ao coordenador pedagógico, representando cerca de 7 teses e 29 dissertações.

Conforme pontuam Pavam e Decari (2014), a expressão coordenação pedagógica surge no contexto de reabertura política do país no final dos anos 1980, quando, nos movimentos de luta por valorização, os professores questionaram também a atuação do supervisor, um especialista cujo papel se restringia ao controle da atividade docente. Tendo em vista as críticas a atuação do supervisor, com a divisão social do trabalho, sendo o supervisor o planejador e o professor executor, o papel do supervisor passou a ser 
criticado. Nesse contexto de negação dos especialistas e cenário de reconfiguração do papel do Estado surge o termo coordenação pedagógica em substituição às nomenclaturas até então utilizadas. Este profissional, então, passa a assumir novas demandas nas escolas e nos sistemas educacionais, entre elas a formação continuada dos professores, seja para realizar programas de formação continuada de professor, seja para promovê-los.

É importante lembrarmos, conforme exposto, que a nova denominação e papel desse profissional ocorre num contexto de reconfiguração do papel do estado brasileiro, que adota o modelo gerencialista de administração com novas tendências como "a utilização de modelos técnicos de formação docente que tomam o mercado como modelo de eficiência, traduzindo-se em estratégias como descentralização, inovações na gestão, na coordenação pedagógica e na docência, além de novas tarefas e responsabilidades aos profissionais da educação" (DUBLANTE; SOUSA, 2017, p. 175).

Professor coordenador pedagógico é outra denominação que aparece em um número significativo de trabalhos, especialmente nas dissertações. Essa questão está relacionada com a forma de ingresso do profissional na carreira, conforme pontuam Placco e Almeida (2012), sendo que em certas redes de ensino o ingresso na carreira de coordenador pedagógico é por meio de concurso publico, já em outras redes trata-se de função gratificada, com ingresso de forma bastante diversificada, sendo uma delas a saída do professor da regência de classe para a coordenação pedagógica, denominando-se na maioria desses casos de professor coordenador pedagógico. Na visão de Figueiredo (2014) trata-se de mais responsabilização aos professores, que no cenário neoliberal necessitam ser flexíveis e eficientes para assumirem outras funções como a de coordenador.

Conforme explicitamos anteriormente, dos 56 trabalhos selecionados, apenas 1 dissertação trata de forma específica das condições de trabalho do coordenador pedagógico, sendo que as demais tem uma relação de proximidade com a temática. Os quadros abaixo demonstram uma síntese 
das abordagens extraídas na leitura dos resumos das teses e dissertações analisadas.

Quadro 3: Temas abordados nas Dissertações

\begin{tabular}{|l|c|}
\hline \multicolumn{1}{|c|}{ RESUMOS DE TEMAS ABORDADOS NAS DISSERTAÇÕES } & QUANT. \\
\hline Condições de trabalho do coordenador pedagógico & 01 \\
\hline Coordenação pedagógica: trabalho coletivo, gestão democrática & 04 \\
\hline O coordenador pedagógico e a formação docente & 14 \\
\hline Processo formativo do coordenador pedagógico & 04 \\
\hline Construção da identidade do coordenador pedagógico & 02 \\
\hline Atividades/experiências/atuação do coordenador pedagógico & 14 \\
\hline Atribuições legais e prática profissional do coordenador pedagógico & 06 \\
\hline
\end{tabular}

Fonte: Elaborado pelos autores, 2017.

Quadro 4: Temas abordados nas Teses

\begin{tabular}{|l|c|}
\hline \multicolumn{1}{|c|}{ RESUMOS DE TEMAS ABORDADOS NAS TESES } & QUANT. \\
\hline Papel do coordenador pedagógico & 03 \\
\hline Dimensão subjetiva do trabalho coordenador pedagógico & 01 \\
\hline O coordenador pedagógico e a formação continuada & 02 \\
\hline A formação continuada do coordenador pedagógico & 01 \\
\hline $\begin{array}{l}\text { As transformações/ressignificações da função do coordenador } \\
\text { pedagógico }\end{array}$ & 02 \\
\hline Trabalho/ políticas do professor pedagogo & 02 \\
\hline
\end{tabular}

Fonte: Elaborado pelos autores, 2017.

Entre os temas abordados sobre o coordenador pedagógico há um destaque para a questão da formação continuada como principal trabalho desse profissional e ainda os processos de sua formação. Os trabalhos de modo geral abordam a importância de uma formação inicial e continuada do coordenador pedagógico como instrumento necessário no processo de atuação desse docente e tratam a formação continuada dos professores 
como uma atividade pedagógica a ser organizada no contexto escolar pelo profissional da coordenação pedagógica.

Entre os trabalhos citamos a tese de Corrêa (2016), intitulada: O cotidiano do coordenador pedagógico na visão da complexidade: práticas de formação continuada no cenário da educação infantil, há uma reflexão sobre a formação continuada que deverá ser concebida em um novo paradigma, pensamento, concepção e organização.

\begin{abstract}
Novo paradigma em relação ao ideário da formação continuada, na ruptura necessária frente às propostas de formação com bases técnicas-reprodutivistas ou terapêuticas, que mais se configuram em estratégias deformativas, na medida que possuem pouco vínculo às necessidades da sociedade globalizada e tecnológica.

Pensamento, no sentido da "nova forma" (MORIN, 2008) de pensar, conceber e efetivamente realizar. De trazer para o centro das propostas da formação continuada o seu ator, o Ser-humano prépós formação: o profissional.

Concepção na atitude vinculativa à realidade, ou seja, a formação continuada contextualizada com a necessidade dos profissionais envolvidos, suas formas de ver e inter-relacionar-se sócioculturalmente.

Organização da formação continuada no sentido das formas de como se estruturam as propostas, quais encaminhamentos são realizados para se atingir com efetividade o processo formador de caráter contínuo (CORRÊA, 2016, p. 116-117).
\end{abstract}

Coadunamos com a concepção de formação continuada defendida por Corrêa (2016) e com as colocações de que cabe ao coordenador pedagógico a organização dos tempos e espaços de formação no ambiente escolar. Todavia, é preciso enfatizar que essa organização não depende apenas do olhar do profissional da coordenação, mas tem relação direta com as condições de trabalho dos profissionais do Magistério que estão inseridos no contexto das escolas, que tem sua estrutura, organização e processos de trabalho relacionados com o contexto social, político e econômico.

Para discussão das condições de trabalho do coordenador pedagógico apresentamos uma análise de seus componentes a partir de duas categorias, tendo em vista as dissertações e teses pesquisadas. 


\section{Algumas categorias de análise a partir das pesquisas}

Levando em conta os componentes das condições de trabalho docente expostas por Oliveira e Vieira (2012), apresentamos a análise desses componentes nas produções acadêmicas analisadas, a partir de duas categorias elaboradas com a leitura de resumos, palavras chaves e introdução das teses e dissertações: a) o trabalho do coordenador pedagógico: tarefas e responsabilidades, tempos e espaços para a realização do trabalho e b) carreira do coordenador pedagógico: admissão, remuneração, jornada e formas de regulação, controle e autonomia.

a) O trabalho do coordenador pedagógico: tarefas e responsabilidades; tempos e espaços para a realização do trabalho.

$\mathrm{Na}$ discussão sobre $\mathrm{O}$ trabalho do coordenador pedagógico destacamos a dissertação de Teixeira (2014) que apresenta um debate sobre o exercício do trabalho do coordenador pedagógico, cuja atividade prioritária é a questão pedagógica, mas que se vê diante de inúmeras demandas burocráticas que acaba por impedir a atuação em projetos pedagógicos das instituições.

Nessa direção temos as abordagens de Campos e Aragão (2012) que chamam a atenção para a necessidade de mudar a "função tarefeira" do coordenador pedagógico no contexto escolar de modo que o mesmo possa assumir efetivamente seu trabalho de formador.

Outro trabalho analisado que destacamos nessa categoria é a dissertação de Sousa (2014) que discute experiência de formação continuada na escola realizada por coordenadores pedagógicos, com implicações importantes na prática pedagógica. Porém o referido estudo questiona o pouco esforço por parte do poder público municipal para traçar uma política pública voltada à formação docente, de forma que a responsabilidade acaba recaindo sobre o coordenador pedagógico e contribuindo para a intensificação do trabalho desse profissional. 
Um aspecto apontado pela tese de Doutorado de Araújo (2013) em pesquisa realizada na rede municipal do Rio de janeiro é que o coordenador pedagógico vem assumindo muitos outros afazeres na escola em função do esvaziamento de pessoal responsável pelas questões técnicas da escola. $O$ autor cita a realidade vivenciada pela rede no momento da pesquisa, onde a maioria das Unidades Escolares contava apenas com a presença do diretor, diretor adjunto e o coordenador pedagógico, existindo assim um acúmulo de funções, impossibilitando em muitos momentos, que o coordenador pedagógico exerça de fato sua função pedagógica nas unidades escolares.

A dissertação de Venâncio (2014) aponta que o coordenador pedagógico reconhece as suas funções. Contudo, diante da falta de professores, imprevistos, emergências e urgências, ele se vê obrigado a avançar em outras funções que não Ihe competem, a fim de que haja um equilíbrio na escola.

No que se refere à organização do trabalho do coordenador pedagógico, a dissertação de Mestrado de Araújo (2015) demonstra que os tempos e espaços de ações pedagógicas nas escolas onde realizou pesquisa são insuficientes para a garantia de uma política de formação contínua do professor.

Gois (2012) na dissertação de mestrado explica que a falta de tempo, - acúmulo de atividades profissionais e institucionais, a limitação orçamentária, a falta de acesso a cursos de formação contínua na área, a carência de leituras condizentes à função que exercem os coordenadores pedagógicos os deixam fragilizados em exercer o papel principal na escola qual seja, a reflexão com os professores sobre suas práticas docentes. Essa autora enfatiza ainda que o desenho da organização escolar não permite um trabalho compartilhado do coordenador pedagógico com seus pares; não há disponibilidade de tempo para compartilhar com a comunidade escolar a devida atenção para pensar e refletir sobre o trabalho realizado.

Na mesma direção dos trabalhos analisados está a pesquisa de Arruda e Colares (2017) realizada na rede municipal de Santarém/Pará, a qual 
mostra que o cotidiano do coordenador pedagógico é assoberbado de emergências, eventos, processos burocráticos e outras demandas que desviam o olhar e as ações desse profissional, causando aos mesmos angústias frente a multiplicidade de exigências as quais são expostos. $\mathrm{Na}$ visão das autoras um dos motivos para essa situação é a falta de clareza quanto ao trabalho a ser desenvolvido por esse profissional.

Essa mesma pesquisa traz reflexões sobre o espaço na estrutura física da escola ocupada pelo coordenador pedagógico, mostrando que nas instituições pesquisadas não há delimitação do local de trabalho do mesmo, o que demonstra a falta de valorização do coordenador desde as políticas de infraestrutura da escola. A partir de dados do Inep, as autoras demonstram que a dificuldade com espaço físico não é restrita ao universo da pesquisa, pois mais de $80 \%$ das escolas brasileiras, entre 263.833 unidades escolares públicas e privadas, tem estrutura elementar, ou seja, não dispõe sequer de sala para professores, o que torna o trabalho do coordenador pedagógico ainda mais difícil.

Destacamos a dissertação de Malewschik (2016) produzida junto ao Mestrado em Educação que discute as condições de trabalho do supervisor escolar na rede municipal de Joinville, apresentando uma lista com 19 itens do Regimento escolar Unificado das escolas da rede municipal de ensino que define as funções do supervisor escolar, sendo questionado se há condição de cumprir tantas atribuições e quais as condições de trabalho em que ocorre a atividade do supervisor escolar.

A pesquisa mostra que uma das atividades que mais se faz presente na rotina do supervisor é a substituição de professores que se ausentam na escola, não havendo estudos sobre os motivos das ausências.

A partir da análise, nota-se que as condições precárias nas instituições escolares, como a falta de espaços e tempos para a formação docente, principal atividade do coordenador pedagógico, acaba dificultando 0 trabalho desse profissional. Além disso, a falta de outros profissionais nas unidades escolares, assim como a formação inicial e continuada leva ao 
desvio de função do coordenador pedagógico, que se vê diante de urgências e emergências que precarizam seu trabalho.

b) Carreira do coordenador pedagógico: admissão, remuneração, jornada e formas de regulação, controle e autonomia.

$\mathrm{Na}$ discussão de componentes das condições de trabalho do coordenador pedagógico como admissão na carreira, formas de remuneração, regulação, controle e autonomia, destacamos alguns trabalhos pesquisados no Banco de teses e dissertações da Capes. Entre as teses elencamos: O trabalho do pedagogo na escola pública do Paraná (BACIUK, 2014); Políticas para o trabalho dos pedagogos na rede estadual de ensino do Paraná (2004-2015): intensificação, burocracia e possibilidades de superação (HADADD, 2016); Transformações ocorridas na função do coordenador pedagógico, na rede estadual da Bahia (1950 a 2011): alguns apontamentos sociopolíticos, legais e históricos (VENAS, 2013) e Coordenação do trabalho pedagógico na rede estadual paulista: desafios, limites e potencialidades (SILVA, 2015).

Entre as dissertações pesquisadas no Banco de teses e dissertações da Capes destacamos: O trabalho do professor coordenador na escola pública paulista - a formação de uma identidade (RIGUETO, 2016); Entre o Administrativo e o Pedagógico: a atuação do supervisor de ensino na rede estadual paulista (NAKANO, 2015); O trabalho do coordenador pedagógico em tempos de mudança (GOIS, 2012); O trabalho e os desafios do professor coordenador na rede municipal de rio claro (FERRI, 2013) e Condições de trabalho do supervisor escolar no ensino fundamental (MALEWSCHIK, 2016).

A partir da tese de Baiuk (2014) percebemos que o trabalho dos pedagogos é desenvolvido em meio a contradições entre o que apresenta a lei e o que o profissional realiza. Na visão da autora,

Documentos que orientam esse trabalho direcionam para o trabalho unitário e uma gestão democrática, contudo, o pedagogo é chamado a desenvolver atividades que não thes são inerentes. Como multitarefeiro, atende à perspectiva gerencial de gestão que, 
como em outras fases, está a serviço do capital, implementando as políticas educacionais que são traçadas pelo Estado.

Discussão semelhante é feita na tese de Hadadd (2016) que investiga as políticas formuladas e implementadas na rede estadual de ensino Paraná de 2004 a 2015 e defende que as políticas para o trabalho dos pedagogos tem se caracterizado pela intensificação, alienação e burocratização do trabalho.

Sobre a autonomia do trabalho do coordenador pedagógico e a sua relação com o controle e regulação do Estado, a dissertação de Rigueto (2016) sobre o trabalho da coordenação pedagógica no contexto de São Paulo, mostra as interferências das políticas neoliberais adotadas pelo Estado na atividade do coordenador pedagógico, atuando este como mediador/articulador entre as políticas do Estado e os professores.

Nakano (2015) na dissertação de Mestrado nos mostra que a maioria dos supervisores de ensino trabalha com o pedagógico e com 0 administrativo, no entanto, obedecendo às diretrizes da Secretaria da Educação, que, por vezes, pode estar carregada do trabalho burocrático, de controle, normas e regulamentos, e distante do ideal de autonomia preconizado nos referenciais teóricos.

A tese de Venas (2013) demonstra uma contradição em torno da autonomia no trabalho dos coordenadores pedagógicos, pois os mesmos participam da equipe gestora como parte executora, mas não participam, na maioria das vezes, dos processos de tomada de decisão.

Na dissertação de Gois (2012) a autora considera que na maior parte dos casos as condições salariais dos coordenadores pedagógicos os levam a exercer outras funções ou ampliar a jornada de trabalho, como forma de aumentar seus rendimentos.

Quanto às formas de admissão do coordenador pedagógico a dissertação de Mestrado de Ferri (2013) ajuda a entender que há uma diversidade de denominações desse profissional e isso tem relação com as formas de ingresso na carreira. A autora esclarece que o termo possui 
diferenciação dependendo da forma de organização da rede municipal ou sistema de ensino da escola (pública/privada), ou mesmo de ordem municipal/estadual, e pode ser encontrado como: Coordenador Pedagógico, Professor Coordenador Pedagógico, Orientador Pedagógico, Pedagogo e Supervisor Pedagógico.

Silva (2015) em sua tese mostra como ocorre a admissão desse profissional na rede pública estadual paulista, sendo o processo elaborado pela resolução SE n 88 de 19-12-2007 a qual estabelece que cada Diretoria de Ensino realize seu processo de designação do docente para a função de professor coordenador, observando o credenciamento, válido por três anos, obtido em processo seletivo que consiste em uma entrevista individual e um projeto para a unidade escolar. É exigida para o exercício da função, a licenciatura plena em qualquer área do conhecimento e três anos como docente da rede estadual em caráter efetivo ou estável na unidade em questão, porém, em não havendo um docente credenciado da própria unidade, a função poderá ser exercida por um docente classificado em outra unidade escolar.

Destacamos nessa categoria também a dissertação de mestrado de Malewschik (2016) que, conforme descrito anteriormente, discute as condições de trabalho do supervisor escolar na rede municipal de Joinville e nesse processo analisa o plano de cargos e salários, sendo o supervisor considerado na legislação como um especialista em educação.

Para o ingresso no trabalho de supervisão escolar se faz necessário o concurso público de provas e títulos, conforme preconizam a Constituição Federal de 1988 e a LDB n 9394/1996. Todavia, a pesquisa de Malewschik (2016), que apresenta um perfil dos supervisores, mostra que apenas $50 \%$ dos que atuam na rede municipal de Joinville são concursados, sendo os demais convidados, remanejados, indicados ou candidataram-se para a função, e assim não adquirem estabilidade nesse cargo, o que, em algumas situações, pode gerar um desconforto para o exercício da função, pois a qualquer momento podem ser substituídos por concursados ou serem transferidos para outras escolas. 
Analisando as condições objetivas da valorização do supervisor escolar, Malewschik (2016) discute, entre outros aspectos, a jornada de trabalho, o piso salarial e a progressão na carreira. Com relação à jornada de trabalho, tendo como referencial o plano de cargos e salários do Magistério, a autora informa que a jornada de trabalho dos especialistas é de 40 (quarenta) horas semanais, sendo específico para os especialistas, diferentemente dos professores que podem optar por 10, 20, 30 ou 40 horas semanais, ressaltando que a jornada de trabalho dos especialistas é dada em hora relógio, ou seja, 1h, já para o professor são horas aulas, ou seja, $45 \mathrm{~min}$ para os anos iniciais ou $48 \mathrm{~min}$ para os anos finais.

No tocante à progressão do supervisor escolar, esta ocorre para todos os profissionais do magistério da rede por Antiguidade ou por Merecimento e por Acesso. A promoção por antiguidade se refere ao tempo de serviço, por merecimento por participação em cursos, e por acesso quando da passagem de uma categoria para outra motivada por habilitação superior.

Dentro da questão da remuneração o piso salarial inicial dos supervisores escolares da rede municipal de Joinville se equipara ao de professor. Todavia não se leva em consideração a qualificação exigida do Supervisor Escolar que é pós-graduação, o que contradiz a Lei $n^{\circ}$ 11.738/2008, que estabelece o piso salarial para os docentes com formação em Ensino Médio e expõe a necessidade de planos de carreira para valorizar as demais formações.

\section{CONSIDERAÇÕES FINAIS}

A análise das produções acadêmicas sobre as condições de trabalho do coordenador pedagógico entre os anos de 2012 e 2016 demonstra que esse profissional recebe diferentes denominações em várias redes de ensino, predominando o termo coordenador pedagógico. Apesar da diferença na nomenclatura há consenso quanto a sua principal atividade, que é a atuação nos processos de formação continuada nas escolas, a qual consideramos ser importante e por isso organizada por um profissional com condições adequadas de trabalho. 
Formação continuada é o conteúdo mais abordado nas teses e dissertações analisadas, sendo as condições de trabalho discutido como um todo em apenas uma dissertação de Mestrado. Os demais trabalhos apresentam um ou outro componente da condição de trabalho docente, entendida aqui na perspectiva apresentada por Oliveira e Vieira (2012).

Notamos que o trabalho a ser desenvolvido pelo coordenador pedagógico (a formação continuada dos professores) tem sido objeto de estudo de muitas pesquisas, porém as condições para a realização desse trabalho, que envolve desde a estrutura física e material ao vínculo de trabalho do profissional, foi discutida por poucos estudos.

A análise das condições de trabalho do coordenador pedagógico a partir da leitura de resumos e introdução de algumas teses e dissertações produzidas no período de 2012 a 2016 mostra que esse profissional encontra inúmeras dificuldades para a realização do seu trabalho, as quais vão desde a estrutura física ao tempo para atuar nos processos de formação docente, além da falta de profissionais no espaço das escolas, que resulta em desvio de função do coordenador pedagógico.

Além disso, algumas pesquisas demonstradas nas teses e dissertações revelam a falta de valorização da função de coordenador pedagógico e cumprimento de legislação no que se refere ao ingresso na carreira. Há registro também de insatisfação de coordenadores pedagógicos quanto à jornada de trabalho e remuneração.

Concluimos com esse estudo do tipo estado da arte que é reduzido o número de trabalhos acadêmicos produzidos nos últimos cinco anos que discutem a condição de trabalho do coordenador pedagógico, considerando todos os seus componentes. Com isso notamos a necessidade da realização de novas pesquisas que revelem questões como vínculo de trabalho desses profissionais, jornada de trabalho, remuneração, espaços de atuação. Consideramos tais questões imprescindíveis, uma vez que o trabalho do coordenador pedagógico tem um significado importante no contexto das escolas e que as condições de trabalho desse profissional repercute em sua atuação. 


\section{REFERÊNCIAS}

ANDERSON, P. BALANÇO DO NEOLIBERALISMO. In: SADER, Emir \& GENTILI, Pablo (orgs.). Pós-neoliberalismo: as políticas sociais e o Estado democrático. Rio de Janeiro: Paz e Terra, 1995. p. 9-23.

ARAÚJO, O. H. A. Formação docente, professor coordenador pedagógico e contexto escolar: diálogos possíveis. 2015. 140 f. Dissertação (Mestrado em Educação). Universidade Federal do Ceará, Fortaleza: Universidade Federal do Ceará/Biblioteca de Ciências Humanas.

\section{ARAUJO, T. C. O. A prática do (a) coordenador (a) pedagógico (a) na Rede} Municipal de Ensino do Rio de Janeiro: formação continuada de professores?. 2013. 162 f. Tese (Doutorado em Educação). Universidade do Estado do Rio de Janeiro, Rio De Janeiro: Rede Sirius.

ARRUDA, E. P. de; COLARES, M. L. I. S. Coordenação pedagógica: prática e prescrições. In: MORAES, L. C. S. de; MOREIRA, C. J. de M. (org.). Formação continuada de coordenadores pedagógicos: discutindo políticas e contextos. São Luiz: EDUFMA, 2017.

BACIUK, N. A. P. O trabalho do pedagogo na escola pública do Paraná. 2014. 198 f. Tese Doutorado em Educação. Universidade Tuiuti do Paraná, Curitiba: Sydinei Lima Santos.

BARROSO, J. O estado, a educação e a regulação das políticas públicas.

Educ. Soc., Campinas, vol. 26, n. 92, p. 725-751, Especial - Out. 2005.

Disponível em <http://cedes.unicamp.br>. Acesso em 25 out. 2016.

BRASIL. Lei $n^{\circ} \mathbf{5} .540$ de 28 de novembro de 1968. Disponível em:

<http://www2.camara.leg.br/fed/lei/1960-1969/lei-5540-28-novembro-1968-

359201-publicacaooriginal-1pl.html>. Acesso em: 29 nov. 2017.

BRASIL. Lei n 9.394 de 20 de dezembro de 1996. Brasília, 1996. Disponível em: <http://www.planalto.gov.br/ccivil_03/leis/L9394.htm>. Acesso em: 10 jun.

2017.

BRASIL. Lei $\mathrm{n}^{\circ} \mathbf{1 1 . 7 3 8}$ de 16 de julho de 2008. Brasília, 2008. Disponível em: <http://www.planalto.gov.br/ccivil_03/_ato2007-2010/2008/lei/l11738.htm>. Acesso em: 10 jun. 2017.

BRASIL. Resolução CNE/CP n 1, de 15 de maio de 2006. Brasília, 2009. Disponível em: v<http://portal.mec.go.br/cne/arquivos/pdf/rcp01_06.pdf>. Acesso em: 20 ag. 2017.

BRASIL. Diretrizes Curriculares Nacionais para a formação inicial em nível superior (cursos de licenciatura, cursos de formação pedagógica para graduados e cursos de segunda licenciatura) e para a formação 
continuada: resolução CNE n², de 1 de julho de 2015. Brasília, 2015.

Disponível em:

<http://portal.mec.gov.br/index.php?option=com_docman\&view=download \&alias=70431-res-cne-cp-002-03072015-pdf\&category_slug=agosto-2017pdf\&ltemid=30192>. Acesso em: 20 ag. 2017.

CAMPOS, E. F. E. A coordenação pedagógica em questão. Jundiai: Paco Editorial, 2015.

CAMPOS, P. R. I.; ARAGÃO, A. M. F. de. O coordenador pedagógico e a formação docente: possíveis caminhos. In: PLACCO, V. M. N. de S.; ALMEIDA, L. R. de (org.). O coordenador Pedagógico: possibilidades de atuação. São Paulo: Loyola, 2012.

CORREA, B. R. do P. G. O cotidiano do coordenador pedagógico na visão da complexidade: práticas de formação continuada no cenário da educação infantil. 2016. 255 f. Tese (Doutorado em Educação). Pontifica Universdade Católica do Paraná, Curitiba: Biblioteca Central da PUCPR.

DIAS, I. S.; ROCHA, H. O. Política de formação continuada: entre o ideal e os limites impostos pelo real aos coordenadores da educação básica das escolas públicas do Maranhão. In: MORAES, L. C. S. de; MOREIRA, C. J. de M. (org.). Formação continuada de coordenadores pedagógicos: discutindo políticas e contextos. São Luiz: EDUFMA, 2017.

DOMINGUES, I. O coordenador pedagógico e a formação contínua do docente na escola. São Paulo: Cortez, 2014.

DUBLANTE, C. A. S.; SOUSA, K. C. S. Coordenação pedagógica: novos caminhos para a melhoria da qualidade da educação. In: MORAES, L. C. S. de; MOREIRA, C. J. de M. (org.). Formação continuada de coordenadores pedagógicos: discutindo políticas e contextos. São Luiz: EDUFMA, 2017.

FERRI, T. H. J. B. O trabalho e os desafios do professor coordenador da rede municipal de Rio Claro. 2013. 130 f. Dissertação (Mestrado em Educação). Universidade Estadual Paulista Júlio de Mesquita Filho/Rio Claro, Rio Claro: IBUNESP-Rio Claro.

FIGUEIREDO, A. H. B. Trabalho docente: condições de trabalho, carreira e salário do magistério da rede pública estadual do Ceará. 2014. 91 f. Dissertação (Mestrado em Educação). Universidade Federal do Ceará, Ceará: Biblioteca de Ciências Humanas.

GOIS, M. G. de. O trabalho do coordenador pedagógico na escola em tempos de mudança. 2012. 132 f. Dissertação (Mestrado em Educação). Universidade Estadual do Ceará, Fortaleza: UECE. 
HADDAD, C. R. Políticas para o trabalho dos pedagogos na rede estadual de ensino do Paraná (2004 - 2015): intensificação, burocracia e possibilidades de superação. 2016.323 f. Tese (Doutorado em Educação). Universidade Tuiuti do Paraná, Curitiba: Sydnei Antonio Rangel Santos.

HARVEY, D. A transformação político econômica do capitalismo do final do século XX. A Condição pós-moderna. São Paulo: Loyola, 1992.

LEHER, R. Valorização do magistério. In: OLIVEIRA, D. A; DUARTE, A. M. C.; VIEIRA, L. M. F. Dicionário: valorização do magistério. Belo Horizonte: UFMG/ Faculdade de Educação, 2010. Disponível em:

<http://www.gestrado.net.br/?pg=dicionário-verbetes\&id=430>. Acesso em 13 jun. 2017.

MALEWSCHIK, A. F. Condições de trabalho do Supervisor Escolar no Ensino Fundamental. 2016. 150 f. Dissertção (Mestrado em Educação). Universidade da Região de Joinville, Joinville: Unoversidade da Região de Joinville UNIVILLE.

NAKANO, É. C. de B. Entre o administrativo e o pedagógico: a atuação do supervisor de ensino na rede estadual paulista. 2015. 138 f. Dissertação (Mestrado em Educação). Centro Universitário Moura Lacerda, Ribeirão Preto: Josefina de Souza Lacerda.

OLIVEIRA, D. A.; VIEIRA, L. F. Condições de trabalho docente: uma análise a partir dos dados de sete estados brasileiros. In: OLIVEIRA, D. A.; VIEIRA, L. F. (org.). Trabalho na educação básica: a condição docente em sete estados brasileiros. Belo Horizonte: Fino Traço, 2012.

OLIVEIRA, D. A.; ASSUNÇÃO, A. Á. Condições de trabalho docente. In: OLIVEIRA, D. A; DUARTE, A. M. C.; VIEIRA, L. M. F. Dicionário: condições de trabalho docente. Belo Horizonte: UFMG/Faculdade de Educação, 2010. Disponível em: <http://www.gestrado.net.br/?.pg=dicionarioverbetes\&id=430>. Acesso em: 13 nov. 2017.

PAVAN, R.; BECCARI, M. M. B. Supervisão educacional: uma abordagem a partir das produções acadêmicas. Disponível em:

http://xanpedsul.faed.udesc.br/arq-pdf/378-0.pdf>. Acesso em set. 2016.

PERONI, V. M. V. Breves Considerações sobre a redefinição do papel do estado. In: PERONI, V. M. V. Política educacional e papel do estado no Brasil dos anos 1990. São Paulo: Xamã, 2003.

PINI, M. E.; MELO, S. D. G. Argentina e Brasil: mudanças e contradições nas políticas educacionais. In: OLIVEIRA, D. A.; PINI, M. E.; FELDFEBER, M. Politicas educacionais e trabalho docente. Belo Horizonte: Fino Traço, 2011. 
PLACCO, V. M. N. de S.; SOUZA, V. L. T. de. O trabalho do coordenador pedagógico na visão de professores e diretores: contribuições à compreensão de sua identidade profissional. In: PLACCO, V. M. N. de S.; ALMEIDA, L. R. de (org.). O coordenador Pedagógico: possibilidades de atuação. São Paulo: Loyola, 2012.

RIGUETO, R. L. O trabalho do professor coordenador na escola pública paulista - a formação de uma identidade. 2016. 136 f. Dissertação (Mestrado em Educação). Universidade Estadual de Campinas, Campinas: Biblioteca Central da Unicamp.

SAVIANI, D. A supervisão educacional em perspectiva histórica: da função à profissão pela mediação da ideia. In: FERREIRA, N. S. C. (Org.). Supervisão educacional para uma escola de qualidade. 2. ed. São Paulo: Cortez, 2000.

\section{SILVA, V. A. Coordenação do trabalho pedagógico na rede estadual} paulista: desafios, limites e potencialidades. 2015. 150 f. Tese (Doutorado em Educação). Universidade nove de julho, São Paulo: Biblioteca Prof. José Storópoli.

SOUSA, L. R. de. A formação continuada de professores na escola mediada pelo coordenador pedagógico: implicações no trabalho docente. 2014. 333 f. Dissertação (Mestrado em Educação). Universidade do Estado do Pará, Belém: Bibliotexa Paulo Freire.

TEIXEIRA, A. M. A supervisão escolar no muncípio de São Paulo: da função a profissão. 2014. 142 f. Dissertação (Mestrado em Educação). Universidade Metodista de São Paulo, São Bernardo do Campo: Biblioteca Dr. Jalmar Bowden.

VENÂNCIO, A. de O. Salas de apoio pedagógico e coordenação pedagógica: implicações no trabalho docente. 2014. 117 f. Dissertação (Mestrado em Educação). Universidade da Região de Joinville, Joinville: Universidade da Região de Joinville - UNIVILLE.

VENAS, R. F. Imaginar o passado, recordar o futuro: as transformações na função de coordenador pedagógico na Rede Estadual da Bahia. 2013. $147 \mathrm{f}$. Tese (Doutorado em Educação). Universidade Federal da Bahia, Salvador: Biblioteca Anísio Teixeira - FACED.

VOSGERAU, D. S. R.; ROMANOWSKI, J. P. Estudos de revisão: implicações conceituais e metodológicas. In: Rev. Diálogo Educ. Curitiba, v. 14, p. 165 189, jan/abr. 2014. 